\title{
Effect of Carbon Nanotube Orientation on Mechanical Properties and Thermal Expansion Coefficient of Carbon Nanotube-Reinforced Aluminum Matrix Composites
}

\author{
Z. Y. Liu • B. L. Xiao $\cdot$ W. G. Wang $\cdot$ Z. Y. Ma
}

Received: 24 May 2014/Revised: 15 June 2014/Published online: 19 September 2014

(C) The Chinese Society for Metals and Springer-Verlag Berlin Heidelberg 2014

\begin{abstract}
Carbon nanotube-reinforced 2009Al (CNT/2009Al) composites with randomly oriented CNTs and aligned CNTs were fabricated by friction stir processing (FSP) and FSP-rolling, respectively. The CNT/2009Al composites with aligned CNTs showed much better tensile properties at room temperature and elevated temperature compared with those with the randomly oriented CNTs, which is mainly attributed to larger equivalent aspect ratio of the CNTs and avoidance of preferential fracture problems. However, much finer grain size was not beneficial to obtaining high strength above $473 \mathrm{~K}$. The aligned CNTs resulted in tensile anisotropy, with the best tensile properties being achieved along the direction of CNT aligning. As the off-axis angle increased, the tensile properties were reduced due to the weakening of the load transfer ability. Furthermore, aligned CNTs resulted in much lower coefficient of thermal expansion compared with randomly oriented CNTs.
\end{abstract}

KEY WORDS: Carbon nanotubes; Metal matrix composites; Mechanical properties; Coefficient of thermal expansion; Friction stir processing

\section{Introduction}

Discontinuously reinforced aluminum matrix composites are recognized to have superior mechanical properties, such as higher strength and stiffness, compared with the aluminum alloys [1-4]. Ceramic particles, such as micron-

Available online at http://link.springer.com/journal/40195

Z. Y. Liu

School of Materials Science and Engineering, Dalian University of Technology, Dalian 116024, China

Z. Y. Liu · B. L. Xiao · Z. Y. Ma (ه)

Shenyang National Laboratory for Materials Science, Institute of Metal Research, Chinese Academy of Sciences,

Shenyang 110016, China

e-mail: zyma@imr.ac.cn

W. G. Wang

School of Mechanical Engineering, Liaoning Shihua University, Fushun 113001, China sized $\mathrm{SiC}$ or $\mathrm{Al}_{2} \mathrm{O}_{3}$ are commonly used as the reinforcements for the aluminum matrix composites due to its low cost and easy availability. Significant increases in strength and moduli are commonly achieved by the reinforcement incorporation. Unfortunately, the machining capability of the composites becomes very poor, especially for the composites with high reinforcement concentrations. The poor machining capability results from the large size and high hardness of the micron-sized reinforcements. Nanosized reinforcements have been considered to be possible solution for machining challenge.

Carbon nanotubes (CNTs), with extremely high elastic modulus $(\sim 1 \mathrm{TPa})$, high tensile strength $(\sim 30 \mathrm{GPa})$ as well as good thermal physical properties, such as low coefficient of thermal expansion $(\mathrm{CTE}, \sim 0 / \mathrm{K})$ and high thermal conductivity, have been considered as an ideal reinforcement for composites [5-9]. While the researches using CNTs as reinforcements have mainly focused on polymer or ceramic matrix, some trials have been made to incorporate CNTs into metal matrix, especially aluminum 
matrix. However, CNTs tend to agglomerate together due to their large aspect ratio and strong Van der Waals' force, and are difficult to disperse into the aluminum matrix [10]. Furthermore, the poor wetting properties between aluminum and CNTs make the CNT distribution problem even worse. The CNT clustering would deteriorate the mechanical and physical properties of the composites. Kuzumaki et al. [11] fabricated CNT/Al composites by dispersing the CNTs by simply mixing and followed by hot-extrusion. No tensile strength increase was found for the composites due to the CNT clustering.

In the past few years, many methods, such as ball milling [12-14], molecular level mixing [15, 16], flaky-powder metallurgy [17], in-situ CNT growth [18, 19], and friction stir processing (FSP) [20-23], have been used to solve the problem of CNT dispersing into the metal matrixes. As a result, enhancement on tensile strength or other physical properties has been obtained. Choi et al. [14] achieved about $100 \%$ strength increase for CNT/Al composites prepared by means of high energy ball milling technique. Kim et al. [24] reported 30\% decrease in thermal expansion coefficient (CTE) of $\mathrm{Cu}$ by $\mathrm{CNT}$ incorporation.

Compared with the above-mentioned fabrication routes, FSP incorporated little oxides into the composites during fabrication and had the advantages to obtain the composites with good combination of strength and ductility. In our previous investigations [20, 22], CNT/2009Al composites with random or aligned CNT orientation were fabricated by FSP and FSP-rolling routes, respectively. The rotating threaded pin leads to severe plastic deformation and material mixing, thereby uniformly dispersing the CNTs into the aluminum matrix. During subsequent hot deformation, such as extrusion and rolling, the CNTs could adjust their axis toward the direction of the material plastic flow.

Although increased tensile strength and decreased CTE have been achieved for the CNT/metal composites, little attentions were focused on the effect of CNT orientations on the properties of the CNT/ metal composites. In this study, two CNT/2009Al composites with random and aligned CNT orientations were fabricated by FSP and FSP-rolling, respectively. The tensile properties and CTE of the composites were investigated. The aim of this study is to understand the effect of CNT orientation on the tensile properties and thermal expansion properties of CNT/Al composites.

\section{Experimental}

\subsection{Raw Materials and Composite Fabrication}

The as-received CNTs provided by Tsinghua University had entangled morphology with outer diameters of 10-20 nm and lengths of several microns (Fig. 1). No extra pre-

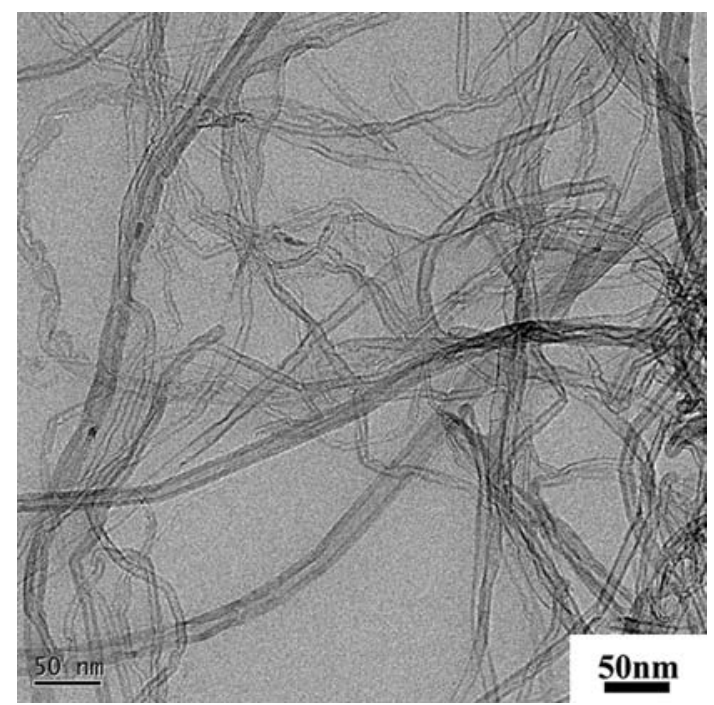

Fig. 1 Morphology of the as-received CNTs

treatments were conducted on the CNTs. The CNTs with volume fractions of $1.5 \%-4.5 \%$ were mixed with $2009 \mathrm{Al}$ ( $\mathrm{Al}-4.5 \mathrm{Cu}-1.2 \mathrm{Mg}$ (in wt $\%)$ ) alloy powders with an average diameter of $10 \mu \mathrm{m}$, in a bi-axis rotary mixer at $50 \mathrm{r} / \mathrm{min}$ for $8 \mathrm{~h}$ with a ball to powder ratio of 1:1. The mixed powders were cold-compacted in a cylinder die, degassed and hotpressed into cylindrical billets. The as-pressed billets were hot forged with steel canning at $723 \mathrm{~K}$ into disk plates with a thickness reducing ratio of 4 .

The CNT/2009Al composites with random CNT orientation were fabricated by in-situ four pass FSP and the detailed procedure has been described in our previous article [20]. For obtaining CNT/2009Al composites with aligned CNT orientation, the forged composites were firstly subjected to 2-pass overlapping FSP, and the FSP zones were machined out and then hot-rolled into sheets with thickness of $1.2 \mathrm{~mm}$. The fabrication detail could be found in our previous article [22].

\subsection{Characterization of the Composites}

The CNT distribution in the matrix was examined using field emission scanning electron microscopy (SEM, Leo Supra 35) and transmission electron microscopy (TEM, Tecnai G2 20). The CNT-Al interface and CNT structure were observed by high resolution TEM (HRTEM, Tecnai G2 20).

The Young's moduli of the composites were measured by the ultrasonic resonance method using RFDAHTVP1750-C (IMCE). The specimens, which had dimensions of $40 \mathrm{~mm} \times 4 \mathrm{~mm} \times 1 \mathrm{~mm}$, were machined with the length parallel to the rolling direction for the rolled composites and parallel to the FSP direction for the FSP 
composites, respectively. The composites were solution treated at $768 \mathrm{~K}$ for $1 \mathrm{~h}$, quenched in water, and then aged naturally for 4 days.

Tensile specimens with a gauge length of $5 \mathrm{~mm}$, a width of $1.5 \mathrm{~mm}$, and a thickness of $1 \mathrm{~mm}$ were machined parallel to the FSP and rolling directions for the FSP and FSProlled composites, respectively. In order to evaluate the tensile anisotropy of the composites with aligned CNTs, the tensile specimens with off-axis angles of $45^{\circ}$ and $90^{\circ}$ from the rolling direction were also machined. Tensile tests were conducted at a strain rate of $1 \times 10^{-3} \mathrm{~s}^{-1}$ at temperatures from 297 to $573 \mathrm{~K}$ using an Instron $5848 \mathrm{mi}$ crotester. At least three specimens were tested for each condition.

Thermal expansion specimens with a diameter of $5 \mathrm{~mm}$ and a length of $20 \mathrm{~mm}$ were machined from the FSP composites along the FSP direction. However, such specimens cannot be obtained from the FSP-rolled composite sheets because of limited thickness of only $1.2 \mathrm{~mm}$. In this case, in order to demonstrate the effect of CNT orientation on the CTE of the CNT/Al composite, the CNT/Al composites with aligned CNTs, fabricated by high energy ball milling (rotation rate of $400 \mathrm{r} / \mathrm{min}$, duration time of $8 \mathrm{~h}$ ) combined with extrusion (extrusion temperature of $723 \mathrm{~K}$, extrusion ratio of 25:1), were used. Linear CTE was measured using a thermal expansion instrument DIL 402 $\mathrm{PC}$ at a heating rate of $5 \mathrm{~K} / \mathrm{min}$. All the CTE specimens were tested from 293 to $473 \mathrm{~K}$.

\section{Results and Discussion}

\subsection{Microstructure of the Composites}

Figure 2a, b shows the CNT distributions in the FSP and FSP-rolled 1.5 vol\% CNT/20009Al composites, respectively. Uniformly dispersed CNTs could be observed in either the FSP or the FSP-rolled composites. The difference is that an obvious CNT alignment along the rolling direction could be observed for the FSP-rolled composite (Fig. 2b). The different CNT orientations resulted from different deformation styles. FSP produces a complicated plastic deformation and the flow direction is along the direction of pin rotation $[25,26]$. The pin is round and the CNTs could not be aligned to a certain direction. In contrast, the rolling induces material flow along a constant direction and the CNTs could adjust their axis toward the rolling direction. As a result, aligned CNTs were formed after rolling. For simplification, the FSP composite with randomly oriented CNTs is named as the random composite and the FSP-rolled composite with aligned CNTs is named as the aligned composite.

Figure 2c shows the HRTEM image of the CNTs in the FSP-rolled composite. CNT-Al interface was clean, smooth, and bonded well without pores. Although the formation of $\mathrm{Al}_{4} \mathrm{C}_{3}$ was reported in some previous investigation [27], the CNT-Al reaction in the FSP-rolled composite was observed to be not severe, and related results have been reported previously [20]. The well-bonded CNT-Al interface means good load transfer efficiency during tension and is beneficial to strength increase.

\subsection{Tensile Anisotropy of the Aligned Composites}

Figure 3 shows the tensile properties of the aligned composites along different directions. The maximum tensile properties were obtained along the CNT aligning direction. As the tensile off-axis angle increased, both the yield strength (YS) and ultimate tensile strength (UTS) were reduced gradually and the lowest values were obtained when the tension was vertical to the CNT alignment direction. And the higher the CNT concentration was, the faster the strength decreased. The elongation had the similar variation trend with the off-axis angle like the strength. Especially, the elongation of the $4.5 \mathrm{vol} \% \mathrm{CNT} / 20009 \mathrm{Al}$
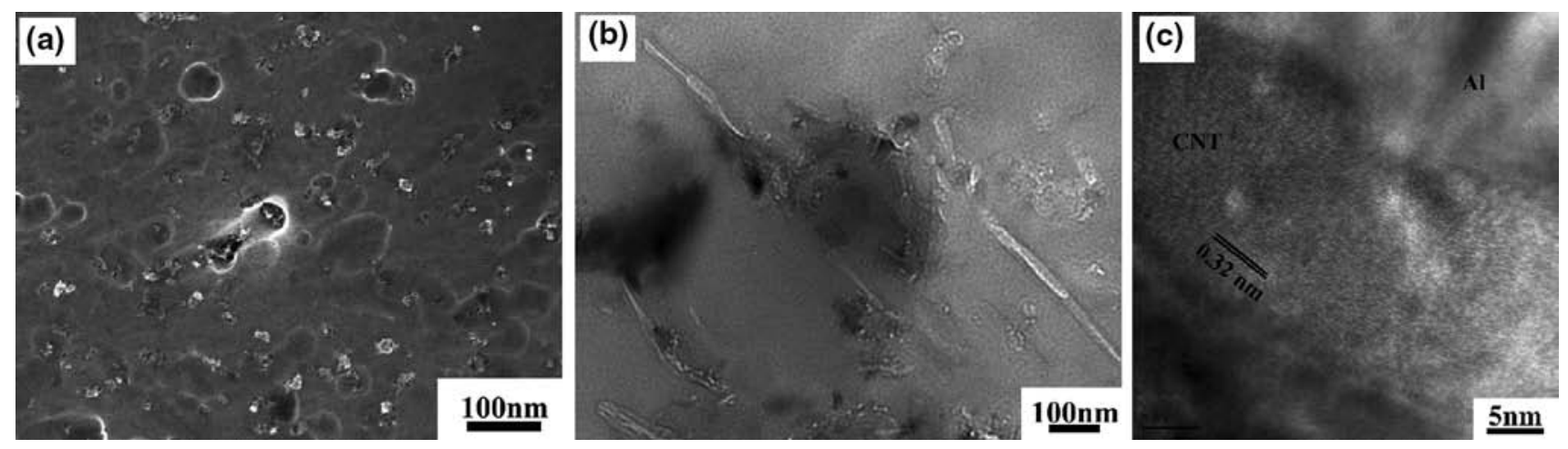

Fig. 2 SEM images showing CNT distribution in FSP a and FSP-rolled b 1.5 vol\% CNT/2009Al composites, and HRTEM image showing CNT in FSP-rolled 4.5 vol\% CNT/2009Al composite c 
composites changed from 5 to $1 \%$ as the off-axis angle increased from $0^{\circ}$ to $90^{\circ}$.

The equivalent aspect ratio of the CNTs could be calculated as follows:

$s_{\text {eff }}=s \cos ^{2} \theta$

where $s_{\text {eff }}$ and $s$ are the equivalent and actual aspect ratio of the CNTs, $\theta$ is the off-axis angle from the CNT alignment direction.

The strength reduction due to weakening of the load transfer ability is:

$\Delta \sigma=\sigma_{\mathrm{m}} \frac{s-s_{\text {eff }}}{4} V_{\mathrm{f}}=\sigma_{\mathrm{m}} \frac{s-s \cos ^{2} \theta}{4} V_{\mathrm{f}}$,

where $\Delta \sigma$ is the YS increment of the composite, $\sigma_{\mathrm{m}}$ is YS of the matrix alloy, and $V_{\mathrm{f}}$ is the volume fraction of CNTs.

The YS of the matrix alloy was about $300 \mathrm{MPa}$. As the $\theta$ increased from $0^{\circ}$ to $45^{\circ}$, the YS reduction for the aligned composites with 1.5, 3 and 4.5 vol\% CNTs are about 17 , 34 and $50 \mathrm{MPa}$, respectively. And as the $\theta$ increased from $45^{\circ}$ to $90^{\circ}$, the YS reduction for the aligned composites with $1.5,3$ and 4.5 vol\% CNTs are also about 17,34 and $50 \mathrm{MPa}$, respectively. This means that the YS of the composites were linearly reduced as the $\theta$ increased from $0^{\circ}$ to $90^{\circ}$, which was in accordance with the experimental result as shown in Fig. 3a. It is indicated that the YS reduction with the off-axis angle increasing resulted from the weakening of the load transfer ability.

Figure 4 shows the fractographs of the aligned composite with $4.5 \mathrm{vol} \% \mathrm{CNTs}$ along different directions. When the tension was parallel to the rolling direction, many tensile dimples could be observed on the fracture surfaces and individually distributed CNTs could be observed at the bottom of the dimples. As the off-axis angle increased to $45^{\circ}$, the dimples titled toward to the direction of CNT alignment. This phenomenon was especially pronounced as the off-axis angle increased further to $90^{\circ}$, with the dimples tilting to the direction that was almost vertical to the tension direction. This means that the load transfer to the CNTs were along the direction of CNT alignment, no matter what tension direction was. Therefore, the load transfer ability was weakened as the off-axis angle increased, because only the load component that was along the tension direction contributed to the strengthening.

\subsection{Room Temperature Tensile Properties}

Table 1 shows the aspect ratio, grain size, and tensile properties of the CNT/2009Al composites with different orientations. It is generally accepted that the load is transferred from the matrix to short fibers at the interfaces parallel to the loading axis. As a composite is loaded, the
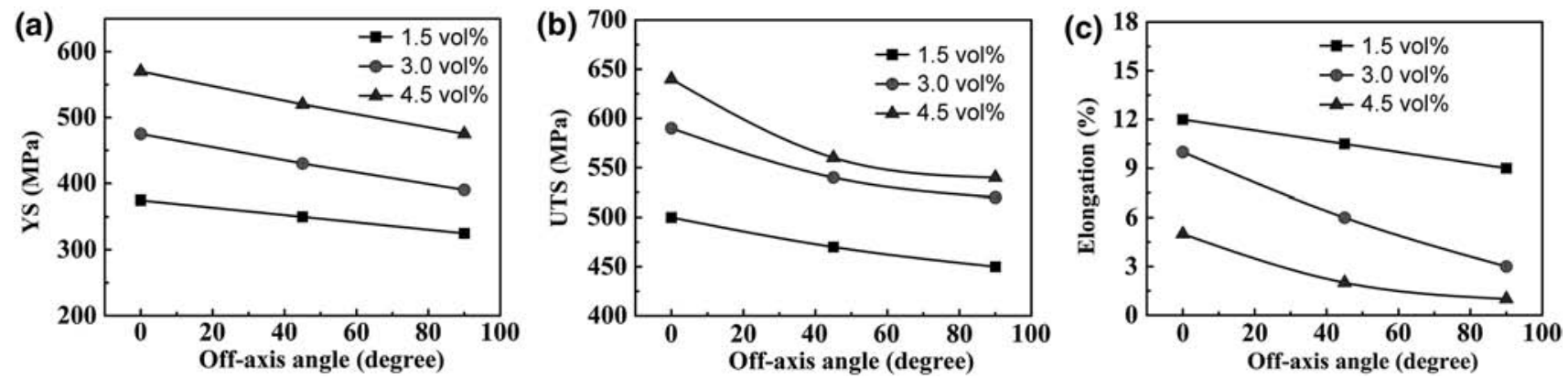

Fig. 3 Variation of tensile properties of the aligned composites with off-axis angle
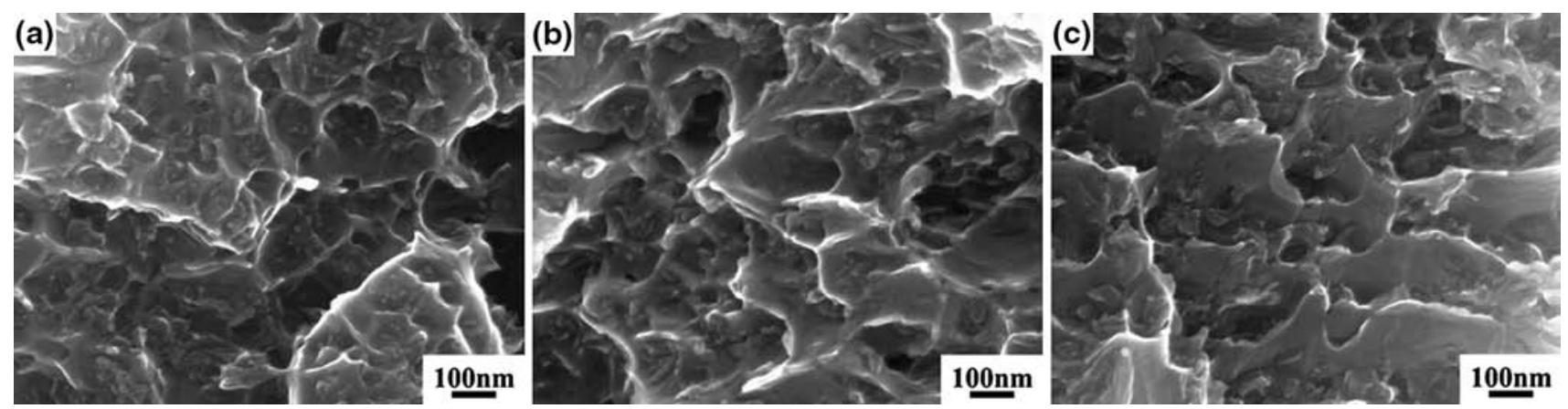

Fig. 4 Fractographs of composites with 4.5 vol\% aligned CNTs with different off-axis angles: a $0^{\circ}$; b $45^{\circ}$; c $90^{\circ}$ 
Table 1 CNT aspect ratios, grain sizes, and tensile properties of CNT/2009Al composites with different CNT orientations

\begin{tabular}{llllllr}
\hline CNT orientation & $\begin{array}{l}\text { CNT } \\
\text { content } \\
(\mathrm{vol} \%)\end{array}$ & $\begin{array}{l}\text { Grain } \\
\text { size } \\
(\mu \mathrm{m})\end{array}$ & $\begin{array}{l}\text { YS } \\
(\mathrm{MPa})\end{array}$ & $\begin{array}{l}\text { UTS } \\
(\mathrm{MPa})\end{array}$ & El (\%) \\
\hline Random orientation & 0 & 4.0 & - & 298 & 409 & 16 \\
& 1.5 & 1.2 & 15 & 385 & 477 & 7 \\
& 4.5 & 0.8 & 15 & 435 & 466 & 2 \\
Aligned orientation & 0 & 4.0 & - & 311 & 415 & 15 \\
& 1.5 & 3.0 & 30 & 380 & 480 & 12 \\
& 3.0 & 0.8 & 30 & 470 & 600 & 10 \\
& 4.5 & 0.5 & 30 & 570 & 640 & 5 \\
\hline
\end{tabular}

fiber and matrix have different axial displacements due to different stiffness of the components. The difference in the axial displacements induces shear strain parallel to the fiber axis at the interface. The shear strain in a short fiber having an off-axis angle would reduce as the angle increased. Thus the load transferred to the short fiber along the fiber axis would also reduce. For the random composites with randomly oriented CNTs, the load transfer efficiency was reduced due to that a large number of CNTs had off-axis angles. As a result, the equivalent aspect ratios of the CNTs in the random composites were much smaller than those in the aligned composites.

4.5 vol\% randomly oriented CNTs resulted in $43 \%$ and $11 \%$ increases in the YS and UTS, respectively. Much larger increases in the YS and UTS of 90\% and 50\% were achieved for the aligned composite. The YS increase due to the load transfer can be calculated by following equation:

$\Delta \sigma_{\mathrm{c}}=\sigma_{\mathrm{m}} \frac{s_{\text {eff }}}{4} V_{\mathrm{f}}$,

where $\Delta \sigma_{\mathrm{c}}$ is the YS increment of the composite.

According to Eq. (3), the YS increase due to the load transfer mechanism for the composites with $4.5 \mathrm{vol} \%$ random and aligned CNTs were 51 and $102 \mathrm{MPa}$, respectively. Furthermore, the grain size of the aligned composite $(\sim 500 \mathrm{~nm})$ was finer than that of the random composite $(\sim 800 \mathrm{~nm})[20,22]$ or the 2009Al alloy $(\sim 4 \mu \mathrm{m})$. That is the $\sigma_{\mathrm{m}}$ for the aligned composite was higher than that for the random composite or the 2009Al alloy, which means further strength increase according to Eq. (3). This accounts for much higher YS increases observed for the aligned composites.

The elongations along the CNT alignment direction for the aligned composites were also much larger than those for the random composites. Aligned composites with 1.5 and 4.5 vol\% CNTs showed elongations of $12 \%$ and $5 \%$, but the random composites with same CNT concentrations showed elongations of only $7 \%$ and $2 \%$. As the CNTs were aligned in the composites, the preferential fracture problems induced by non-simultaneous CNT debonding

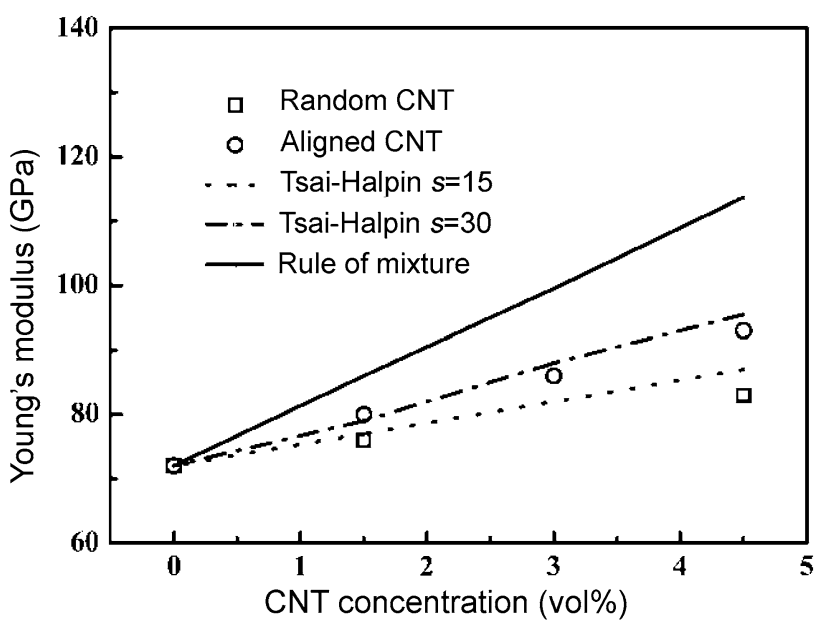

Fig. 5 Moduli of the CNT/2009Al composites with different CNT orientations

associated with randomly oriented CNTs were avoided. This also means that the matrix alloy could be hardened to a much higher stress level in the aligned composites than that in the random composites. Therefore, the elongations as well as the UTS of the aligned composites were much higher.

Figure 5 shows the Young's moduli of the random composites and aligned composites. The aligned composites had much higher moduli than the random composites, which was mainly attributed to different load transfer efficiencies resulting from the CNT orientation. The moduli of the short fiber-reinforced metal matrix composites can be estimated using the Tsai-Halpin equation:

$E_{\mathrm{c}}=E_{\mathrm{m}}\left(1+\xi \eta V_{\mathrm{f}}\right) /\left(1-\eta V_{\mathrm{f}}\right)$,

the parameter $\eta$ being given by the following equation:

$\eta=\left(E_{\mathrm{p}} / E_{\mathrm{m}}-1\right) /\left(E_{\mathrm{p}} / E_{\mathrm{m}}+\xi\right)$,

the parameter $\xi$ being given by the following equation:

$\xi=s+40 V_{\mathrm{f}}^{10}$,

where $E_{\mathrm{m}}$ and $E_{\mathrm{p}}$ are the Young's modulus of the matrix and CNT, respectively. The moduli calculated by TsaiHalpin equation are also shown in Fig. 5. The calculated values were in good agreement with the experimental ones, which indicated that the aligned composites with higher equivalent aspect ratio of CNTs exhibited higher ability to transfer load from the matrix to the CNTs.

\subsection{Elevate Temperature Tensile Strength}

Figure 6 shows the elevated temperature tensile strength of the CNT/2009Al composites. For the random composites, the tensile strength of the $4.5 \mathrm{vol} \% \mathrm{CNT} / 2009 \mathrm{Al}$ was lower 


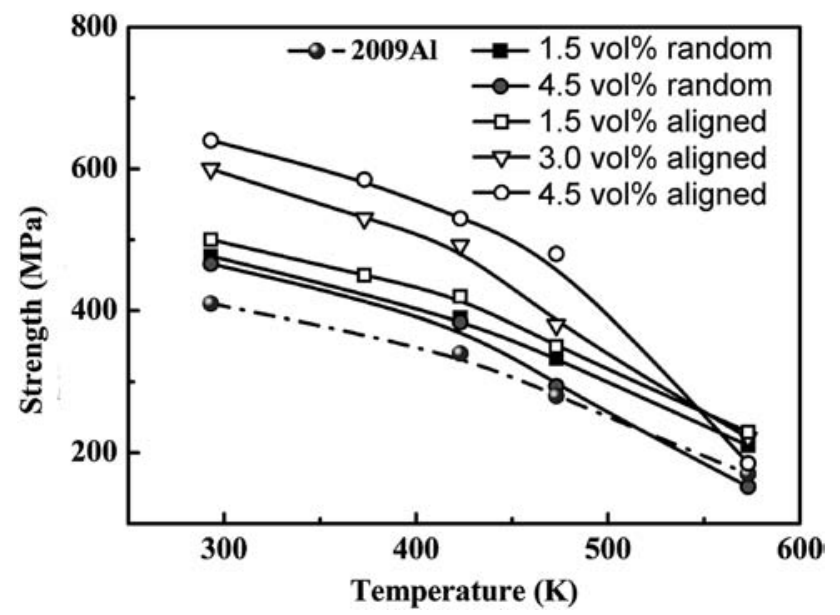

Fig. 6 Elevated temperature tensile properties of the CNT/2009Al composites

than that of the 1.5 vol\% CNT/2009Al composites. As the temperature increased to above $473 \mathrm{~K}$, the strength of the 4.5 vol\% CNT/2009Al composites was even lower than that of the matrix alloy. For the aligned composites, higher tensile strengths were achieved for the composites with higher CNT concentrations at temperatures of 293-473 K. The aligned composites had much higher strength than the random composites. This indicates that the load transfer mechanism could still play a role in strengthening the composite at higher temperatures of $293-473 \mathrm{~K}$, and thus the aligned composites had much higher elevated temperature strengths.

As the temperature increased from 293 to $473 \mathrm{~K}$, the strength of the composites reduced gradually. It is well known that with increasing temperature, the Peierls stress decreases and the dislocation can easily slip and climb in the matrix, and thus the matrix alloy is gradually softened. According to Eq. (3), the strength of the composites was also gradually decreased. However, as the temperature increased further to above $473 \mathrm{~K}$, the strength of the composites, especially the $4.5 \mathrm{vol} \% \mathrm{CNT} / 2009 \mathrm{Al}$, was reduced much faster.

Figure 7 shows the typical fractographs of the composites under different temperatures. At $373 \mathrm{~K}$, both the random composites with 1.5 vol\% CNT and aligned composites with 4.5 vol\% CNT showed relatively deep dimples, and many CNTs were observed at the bottom of the dimples. However, as the temperature increased to $573 \mathrm{~K}$, the composites showed obvious intergranular fracture. Furthermore, the pulled-out CNTs were very short and only the tips of CNTs could be observed. This implies that the fracture mainly occurred at the grain boundaries of the matrix and the bonding strength of the CNT-Al interface was still stronger than the strength of the $\mathrm{Al}$ matrix.

At room temperature, the very fine matrix grains could strengthen the composites. However, this situation changed
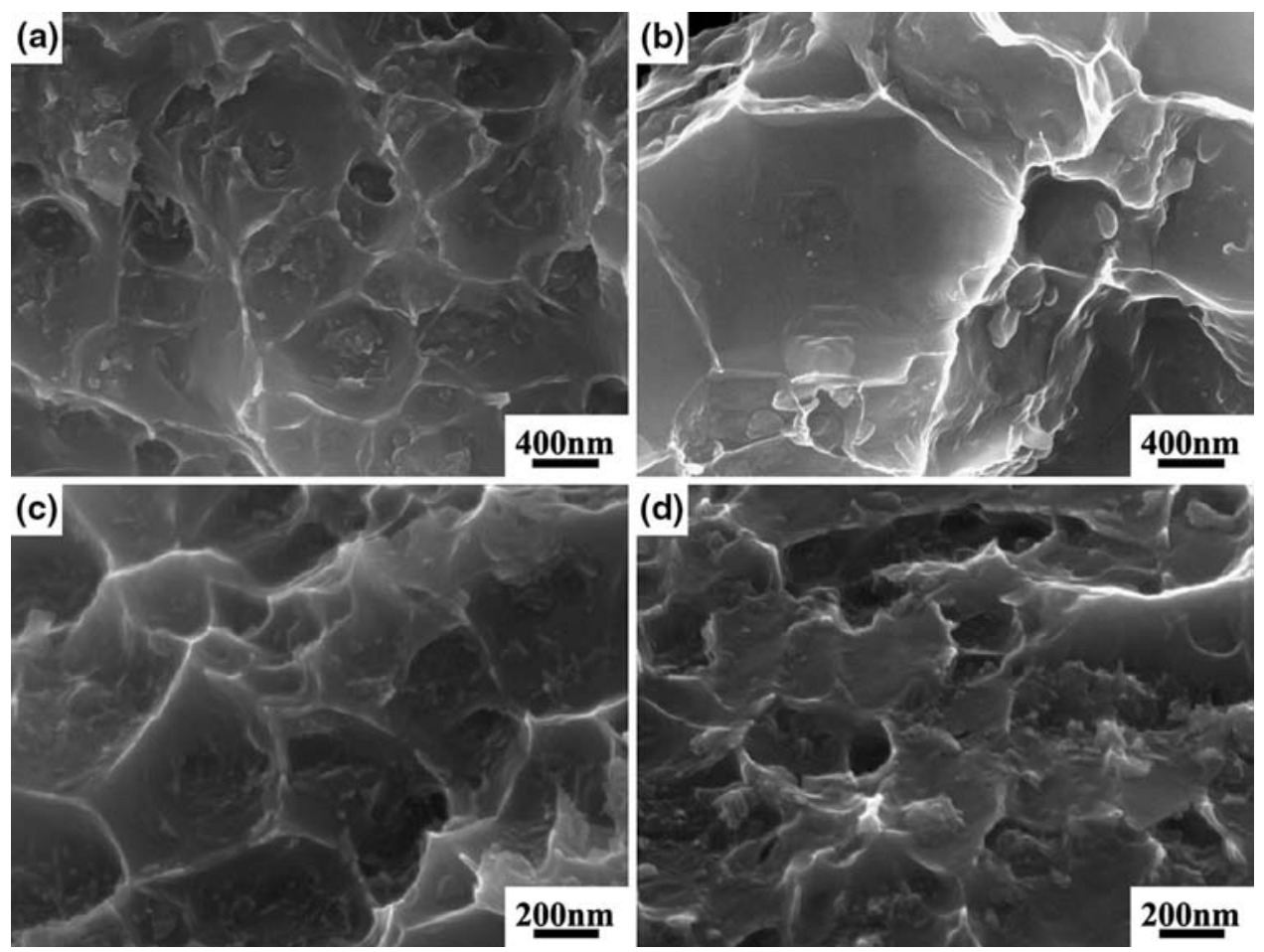

Fig. 7 Fractographs of composites with 1.5 vol\% random CNT at $373 \mathrm{~K}$ a and $573 \mathrm{~K}$ b, and composites with 4.5 vol\% aligned CNT at $373 \mathrm{~K}$ c and $573 \mathrm{~K} \mathrm{~d}$ 
as the temperature increased to an equi-cohesive temperature, above which the grain boundaries are weaker than the grain inner [28]. For the 4.5 vol\% CNT/2009Al composites with random or aligned CNTs, the grain sizes were 800 and $500 \mathrm{~nm}$, respectively. The much refined grain size means the more grain boundaries in the composites. As the temperature increased to above the equi-cohesive temperature, the matrix strength in the composites with finer grains was reduced much faster than that with the coarser grains. And thus, the strength of $4.5 \mathrm{vol} \% \mathrm{CNT} / 2009 \mathrm{Al}$ composites reduced much faster than other composites.

\subsection{CTE of the Composites}

Figure 8 shows the CTE of the random composites and aligned composites. The CNT incorporation resulted in decreased CTE, and the aligned composites showed a much faster CTE reduction. This indicates that the CNTs, especially the aligned CNTs could effectively constrain the thermal expansion of the aluminum matrix. In order to understand the thermal expansion behavior of the composites, it is important to compare the experimental results with theoretical predictions. Schapery's model was usually used to evaluate the CTE of the composites [29].

According to the Schapery's model, the CTE of the composites can be approximately calculated by

$\alpha_{\mathrm{c}}=\frac{E_{\mathrm{p}} \alpha_{\mathrm{p}} V_{\mathrm{f}}+E_{\mathrm{m}} \alpha_{\mathrm{m}}\left(1-V_{\mathrm{f}}\right)}{E_{\mathrm{p}} V_{\mathrm{f}}+E_{\mathrm{m}}\left(1-V_{\mathrm{f}}\right)}$

where $\alpha_{c}, \alpha_{p}, \alpha_{m}$ are the CTEs of the composites, CNTs, and matrix alloy.

The $\alpha_{\mathrm{p}}$ and $\alpha_{\mathrm{m}}$ values of 0 and $23.6 \times 10^{-6} \mathrm{~K}^{-1}$, respectively, were used for calculation and the results are shown in Fig. 8. When the CNTs were randomly oriented

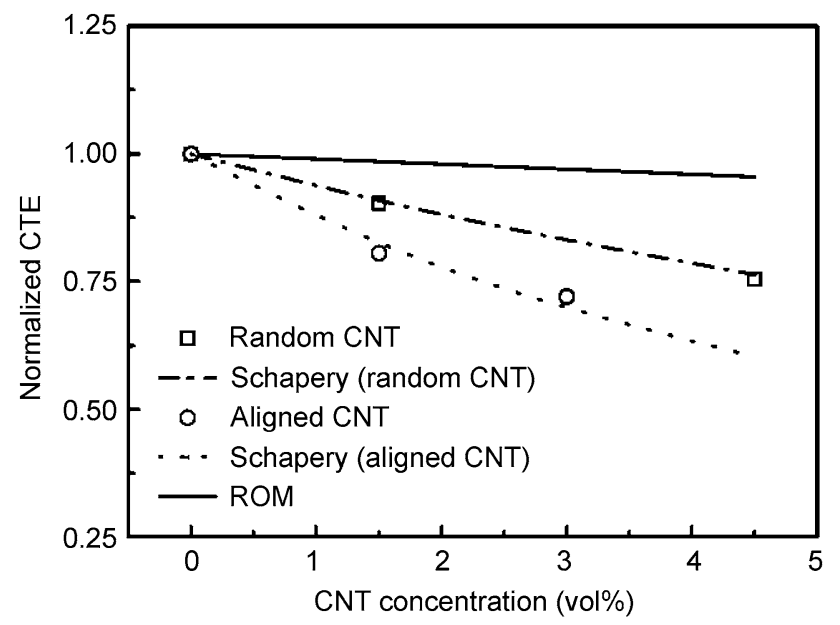

Fig. 8 Variation of normalized CTE of the random and aligned composites with CNT concentration in the composites, the equivalent $V_{\mathrm{f}}$ was only a half of the actual volume fraction. For comparison, the CTE predicted by rule of mixture (ROM) was also added.

It is clear that the CTEs predicted by Schapery's model are in good agreement with the experimental data. The CNT aspect ratio in the random composites were only about half of that in the aligned composites. This demonstrates that the CNTs in the aligned composites had a much higher efficiency to transfer strain from the matrix to the CNTs, and thus the CNT-Al interfaces could effectively constrain the matrix during thermal expansion.

\section{Conclusions}

The CNT/2009Al composites with random and aligned CNTs were fabricated by FSP and FSP-rolling, respectively. The aligned composites showed much higher yield strength, ultimate tensile strength, and elongation as well as Young's moduli compared with the random composites, which is mainly attributed to larger equivalent aspect ratio of the CNTs and avoidance of preferential fracture problems.

The aligned composites exhibited a pronounced tensile anisotropy. The best tensile properties were achieved along the CNT aligning direction, and both of the yield/tensile strength and elongation decreased as the off-axis angle increased from $0^{\circ}$ to $90^{\circ}$, which mainly resulted from the weakening of the load transfer ability.

The aligned composites had much higher elevated temperature tensile strength at 293-473 K, compared with the random composites. The strength of the $4.5 \mathrm{vol} \% \mathrm{CNT} /$ 2009Al composites decreased much faster as the temperature increased to above $473 \mathrm{~K}$, mainly due to the fine grain sizes.

The CNT incorporation resulted in lower CTE in the CNT/2009Al composites compared with the matrix alloy, and the CTE could be well described by the Schapery's model. The aligned CNTs had a much higher efficient constraining effect due to large equivalent aspect ratio.

Acknowledgments This work was financially supported by the National Basic Research Program of China (Nos. 2011 CB932603 and 2012CB619600), and the National Natural Science Foundation of China (No. 51331008).

\section{References}

[1] D.B. Miracle, Compos. Sci. Technol. 65, 2526 (2005)

[2] J.M. Torralba, C.E. da Costa, F. Velasco, J. Mater. Process. Technol. 133, 203 (2003)

[3] Z.Y. Liu, Q.Z. Wang, B.L. Xiao, Z.Y. Ma, Y. Liu, Acta Metall. Sin. 46, 1121 (2010). (in Chinese)

[4] J.S. Moya, S. Lopez-Esteban, C. Pecharroman, Prog. Mater Sci. 52, 1017 (2007) 
[5] P. Ajayan, O. Zhou, Applications of Carbon Nanotubes (Springer, Berlin, 2001), p. 391

[6] M. Trojanowicz, Trends Anal. Chem. 25, 480 (2006)

[7] A. Krishnan, E. Dujardin, T.W. Ebbesen, P.N. Yianilos, M.M.J. Treacy, Phys. Rev. B 58, 14013 (1998)

[8] Z. Han, A. Fina, Prog. Polym. Sci. 36, 914 (2011)

[9] E.T. Thostenson, Z. Ren, T.W. Chou, Compos. Sci. Technol. 61, 1899 (2001)

[10] S.R. Bakshi, D. Lahiri, A. Agarwal, Int. Mater. Rev. 55, 41 (2010)

[11] T. Kuzumaki, K. Miyazawa, H. Ichinose, K. Ito, J. Mater. Res. 13, 2445 (1998)

[12] Z.Y. Liu, S.J. Xu, B.L. Xiao, P. Xue, W.G. Wang, Z.Y. Ma, Compos. A 43, 2161 (2012)

[13] S.J. Xu, B.L. Xiao, Z.Y. Liu, W.G. Wang, Z.Y. Ma, Acta Metall. Sin. 48, 882 (2012). (in Chinese)

[14] H.J. Choi, J.H. Shin, B.H. Min, J.S. Park, D.H. Bae, J. Mater. Res. 24, 2610 (2009)

[15] D.H. Nam, S.I. Cha, B.K. Lim, H.M. Park, D.S. Han, S.H. Hong, Carbon 50, 2417 (2012)

[16] D.H. Nam, Y.K. Kim, S.I. Cha, S.H. Hong, Carbon 50, 4809 (2012)

[17] L. Jiang, G. Fan, Z. Li, X. Kai, D. Zhang, Z. Chen, S. Humphries, G. Heness, W.Y. Yeung, Carbon 49, 1965 (2011)
[18] L. Cao, Z. Li, G. Fan, L. Jiang, D. Zhang, W.J. Moon, Y.S. Kim, Carbon 50, 1057 (2012)

[19] C. He, N. Zhao, C. Shi, X. Du, J. Li, H. Li, Q. Cui, Adv. Mater. 19, 1128 (2007)

[20] Z.Y. Liu, B.L. Xiao, W.G. Wang, Z.Y. Ma, Carbon 50, 1843 (2012)

[21] Z.Y. Liu, B.L. Xiao, W.G. Wang, Z.Y. Ma, Compos. Sci. Technol. 72, 1826 (2012)

[22] Z.Y. Liu, B.L. Xiao, W.G. Wang, Z.Y. Ma, Carbon 62, 35 (2013)

[23] Z.Y. Liu, B.L. Xiao, W.G. Wang, Z.Y. Ma, Carbon 69, 264 (2014)

[24] K.T. Kim, J. Eckert, G. Liu, J.M. Park, B.K. Lim, S.H. Hong, Scr. Mater. 64, 181 (2011)

[25] R.S. Mishra, Z.Y. Ma, Mater. Sci. Eng. R 50, 1 (2005)

[26] Z.Y. Ma, Metall. Mater. Trans. A 39, 642 (2008)

[27] H. Kwon, M. Estili, K. Takagi, T. Miyazaki, A. Kawasaki, Carbon 47, 570 (2009)

[28] M. Nganbe, M. Heilmaier, Int. J. Plast. 25, 822 (2009)

[29] T.W. Clyne, P.J. Withers, An Introduction to Metal Matrix Composites (Cambridge University Press, Cambridge, 1993), p. 120 